\title{
Informales de uniforme: trabajadoras de salones de belleza en Santiago, Chile
}

\section{Rosario Palacios*}

Perfiles Latinoamericanos, 26(51)

2018 | pp. $149-165$

DOI: $10.18504 / \mathrm{pl} 2651-006-2018$

\section{Resumen}

Este artículo examina la forma en que la economía del trabajo flexible afecta a un grupo de trabajadoras de salones de belleza en Santiago, Chile. A este no se le da contrato laboral y se le paga como si brindara un servicio independiente, aunque en realidad dependa de las reglas que le imponen los jefes. Dicho tipo de empleo corresponde a un nuevo arreglo en el contexto de la informalidad urbana y tiene implicancias presentes y futuras respecto de la seguridad social y la incertidumbre. Con base en la observación etnográfica en cuatro salones de belleza, se describe cómo la creencia corporeizada de ser una trabajadora independiente ayuda a enactar muchos de los atributos requeridos por la economía del trabajo flexible.

\begin{abstract}
This article examines how flexible work economy has been affecting a group of beauty salons' workers in Santiago, Chile. They do not have a work contract and receive their payment as if they were giving an independent service, but depend on the rules their bosses impose them. The kind of work described in the article appears to be a new arrangement within the context of urban informality, which has present and future implications regarding social security and uncertainty. Drawing on ethnographic observation in four beauty salons, I describe how the embodied belief of being an independent worker helps to enact many skills required by the flexible work economy.
\end{abstract}

Palabras clave: informalidad, flexibilidad laboral, disciplina, etnografía, salones de belleza, sociología del trabajo.

Keywords: Informality, work flexibility, discipline, ethnography, beauty salons, sociology of work.

* PhD Sociology, London School of Economics and Political Science; MSc Urban Planning, Columbia University. Investigadora Asociada, Pontificia Universidad Católica de Chile | r.palacios@uc.cl 


\section{Introducción}

E

trabajo informal ha sido permanente objeto de estudio de las ciencias sociales. En la década de 1970, el concepto de sector informal se usó para designar principalmente las actividades de subsistencia de quienes laboran en los segmentos marginales de la economía (Hart, 1970; OIT, 1972; Tokman, 2007). Desde entonces se ha intentado definir qué lo caracteriza, aunque con el predominio de la investigación enmarcada en la inequidad social, desde el punto de vista de las brechas existentes en las oportunidades de empleo, calidad de las condiciones de trabajo e ingresos que redunda este (Katzman \& Wormald 2002). En suma, el sector informal ha sido visto como el excedente de mano de obra por empleo.

El presente artículo toma un camino distinto, dado que en la actualidad el trabajo informal ya no es solo asociable a actividades de subsistencia ni necesariamente es poco productivo. Su fuerte relación con la pobreza ha sido cuestionada e incluso hay quienes describen empresas estables, exitosas y dinámicas en dicho sector. Hoy la informalidad además de no ser un rasgo exclusivo de los países subdesarrollados, se la relaciona con la falta de regulación de las condiciones laborales por parte del Estado. Alejandro Portes la ha visto como algo vinculado al capitalismo tardío, a la flexibilización de las leyes laborales y a diversas prácticas que preceden y que son funcionales al desarrollo de la economía capitalista. Las actividades informales son entonces todas las "que no han sido reguladas por el Estado en entornos en que actividades similares están reguladas" (Portes, 2010: p. 133. Traducción propia).

El trabajo informal en el siglo xxI, junto con ser una importante fuente de empleo, productos y servicios para los grupos de bajos ingresos, contribuye significativamente al producto geográfico bruto y se compone de una amplia gama de ocupaciones: antiguas formas de trabajo informal y nuevas como los empleos temporales, trabajos en el domicilio para grandes industrias, trabajos creativos independientes y diversas formas de comercio. El trabajo informal es funcional al formal y dentro del sector formal de la economía existen bolsones que lo contienen.

El intenso desarrollo de investigaciones desde la economía y la política sobre la informalidad, hace patente que hace falta contribuir desde su enfoque cultural para fortalecer otro que analice los trabajadores informales como individuos y no solo como unidades productivas; así se aportaría al diseño y puesta en práctica de políticas sociales. En esta perspectiva se comprendería la exploración de la dimensión productiva del trabajo informal y de las relaciones sociales que le son inherentes, una cuestión que conduce a examinar las prácticas de trabajo cotidiano de los individuos y sus trayectorias laborales. Una visión cultural (Abra- 
mo, 1998) toma como eje de análisis los procesos de formación de sentido que realizan los individuos en relación con sus prácticas de trabajo informal. Esta investigación se lleva a cabo justo en la intersección de las prácticas laborales de un grupo de trabajadores (utilizando una aproximación etnográfica) con los arreglos económicos concretos asociados a un tipo de trabajo en el marco de una economía capitalista flexible.

\section{Independientes/dependientes, una forma de informalidad}

Voy a un local en el centro comercial Colorado y pido que me depilen. La seńora de la caja me manda al box 5. Depilación Manquehue existe desde que se inauguró el centro comercial Colorado en los años ochenta y ha ido creciendo. Antes solo ofrecían servicio de depilación, hoy es también peluquería. Me atiende Inge, una señora de unos cuarenta y tantos ańos. Me depila media pierna, lo hace rápido, en quince minutos estoy lista. Me despido y me acerco a la caja a pagar. "Son cuatro mil", ${ }^{1}$ me dice la cajera. Pago y ella me entrega la boleta. La boleta dice en su encabezado: Inge Solange Parra. Estilista. (Notas de campo, 26 de agosto, 2010).

La situación descrita en mis notas de campo corresponde a la forma de operar de un grupo de trabajadoras ${ }^{2}$ a las que llamaré independientes/dependientes. Son personas sin contrato laboral con la empresa para la que trabajan, pero dependen de esta porque es en sus instalaciones y bajo sus reglas que ejecutan su labor. Siguiendo a Portes \& Haller (2004: pp. 10-11), las personas que entregan boleta, pero que no pagan por su seguro de salud y previsión, serían trabajadoras informales. Esto significa que las trabajadoras de salones de belleza sin contrato laboral no aportan automáticamente a un fondo para su jubilación ni a un seguro de salud, ya que en Chile ambos están asociados al contrato, en consecuencia serían trabajadoras informales.

Los independientes que aportan al sistema de pensiones y de salud pagando por su cuenta son profesionales en su mayoría y pertenecen al segmento chileno de ingresos medios y altos (Henríquez, Cárdenas \& Selamé, 2005). Para las trabajadoras independientes con bajos ingresos este pago se dificulta pues significa un porcentaje muy alto (12\% para el sistema de pensiones y $7 \%$ para el de salud) y su prioridad es tener liquidez en el presente más que asegurar su futuro. Por ello con cierta frecuencia no cuentan con seguridad social.

1 Cuatro mil pesos chilenos equivalen a ocho dólares americanos, aproximadamente. El tipo de cambio vigente es de quinientos pesos chilenos por un dólar.

2 En el artículo usaré trabajadoras, así, en femenino, para referirme a mujeres y hombres. 
Estas trabajadoras independientes/dependientes son, digámoslo así, menos informales que aquellas por cuenta propia que no dan boleta, como las de subsistencia de ingresos bajos que ofrecen servicios de lavandería, costura y gasfitería, entre otros, que no alcanzan a ser formales. A diferencia de las trabajadoras informales tradicionales descritas por Hart (1970), las que boletean no disponen libremente de su tiempo y laboran bajo las órdenes de un jefe. Su libertad es limitada y varía según las circunstancias. En un extremo se encuentran las que obtienen lo mejor de su arreglo laboral debido a su experiencia, el valor que entregan a su trabajo y a la forma en que desarrollan su individualidad (Beck, 2003; Foucault, 1988; Martuccelli, 2007; Rose, 1998), mientras que, en el otro, están las que se llevan lo peor de los dos mundos, del asalariado y del independiente.

Las trabajadoras independientes que se asocian a una empresa pero que operan como autónomas, esto es, con solo un acuerdo de palabra para ejercer su oficio en la organización que las recibe, se hallan en casi todos los salones de belleza de Santiago donde las estilistas entregan una boleta con su nombre y no con el del salón y, por lo tanto, deben pagar por cuenta propia el impuesto único laboral. Esta modalidad se repite en oficios como el de mecánico, electricista, gasfíter, jardinero o mueblista, los que operan bajo el alero de compañías de seguros y megatiendas de hogar; así como también en el trabajo de cuidadoras ligadas a clínicas y casas de reposo. ${ }^{3}$

\section{Metodología}

En el marco de un proyecto de investigación sobre las trabajadoras llamadas informales, ${ }^{4}$ pertenecientes a los estratos socioeconómicos bajo y medio bajo en la ciudad de Santiago, se observaron las vidas cotidianas de 48 personas. El principal objetivo era describir su forma de trabajo y explorar los significados que ellos y ellas atribuían a su actividad. Sin ánimo de agotar las figuras de trabajo informal que pueden existir en Santiago, se identificaron varios de sus distintos nichos y se estudiaron alrededor de cinco a seis casos en cada uno de ellos. Fue así que de los 48 individuos observados, cinco corresponden a trabajadoras independientes/dependientes.

Los casos analizados de personas que trabajan ligadas a una empresa, pero por cuenta propia, pertenecen al ámbito de los salones de belleza: una mani-

3 Este tipo de trabajo es diferente al independiente profesional free lance, que en general no establece una relación permanente con una sola empresa ni trabaja en sus instalaciones, lo que lo hace "verdaderamente independiente"; es el caso del teletrabajo. Véase Henríquez, Cárdenas \& Selamé (2005).

4 Fondecyt Postdoctorado 3100002, 2010, Conicyt, Chile. 
curista, una masajista, un podólogo, una depiladora y un peluquero. Los estilistas entregan una boleta de servicios al cliente a su nombre, pero el precio por el servicio lo decide el salón, el cual retiene para sí un porcentaje del pago que varía entre 65 y $40 \%$.

$\mathrm{El}$ acceso a los informantes fue posible actuando como cliente de cuatro salones de belleza. Luego de conocer a varias de las empleadas, se solicitó a algunas participar en la investigación, sin pasar por sus jefes. Es por eso que se ha resguardado la privacidad de la información que ellas entregaron fuera del control de sus empleadores.

Este esquema plantea preguntas éticas sobre el tratamiento de la información, ya que con todos los informantes se forjó una forma de complicidad, fortalecida por la conveniencia económica que les reportaba que me atendiera con ellas varias veces, lo cual debió tenerse muy presente durante el análisis de los datos.

Se utilizó una aproximación etnográfica (Palacios, 2011), es decir, que se intentó aprehender el mundo de los informantes mediante repetidas observaciones participantes y entrevistas en profundidad sobre temas específicos. Los tiempos de espera, además de los de atención, fueron documentados en notas de campo y varias de las conversaciones fueron grabadas y transcritas. Esta forma de recolectar los datos provocó que para determinados casos se disponga de bastante más información que para otros, ya que el número de atenciones fue dispar. Por ejemplo, las sesiones con el podólogo fueron dos, pero diez con la manicurista y la masajista.

La información recogida se ordenó y analizó de manera reflexiva, sin imponer categorías preconcebidas e intentando siempre mostrar lo que relevaban los entrevistados. En tal sentido, si bien se usó una aproximación cercana a la lectura inductiva de los datos, no hay pretensiones de categorizar los hallazgos en un marco teórico, sino de describir de manera densa (Geertz, 1973: pp. 19-40; Savage, 2009) a este grupo de trabajadoras informales en el Santiago contemporáneo. Se privilegió mostrar la diversidad de sus prácticas laborales evitando su agrupación y reducción a las tipologías. El estudio no aspira a entregar una visión exhaustiva de todos los arreglos entre trabajadoras independientes/dependientes en la ciudad, sino más bien una muestra de lo que está ocurriendo y que fue identificado en esta investigación.

\section{Las historias}

Vanesa tiene veinte años y es manicurista en un salón de belleza ubicado en un centro comercial. El local, pequeño y sin luz natural, se esconde en un ala que da al área de estacionamientos; aun así, ella tiene bastantes clientes ya que 
el lugar pertenece a una conocida cadena de servicios de manicura y pedicura. Vanesa empezó a trabajar hace tres meses, después de haberlo hecho por otros seis con la competencia en Santiago Oriente. A pesar de haberse preparado por un año estudiando la carrera de Estética Integral, debió de seguir una capacitación cuando empezó a trabajar en la manicura y la pedicura. Era su primer empleo de este tipo y atendió por dos semanas de forma gratuita para aprender la rutina que utilizaba la compañía para estos servicios. Luego, cuando ya cobró por sus tratamientos, le descontaban un monto extra mensual correspondiente a la capacitación que había recibido y que estaba valorada en cien mil pesos. Según Vanesa, fue un cobro excesivo y lo recuerda como una más de las injusticias que vivió mientras laboró en ese lugar. Finalmente, se peleó con su supervisora y dejó el trabajo.

En su nuevo empleo - muy similar al anterior-, Vanesa viste el uniforme que le dan y cumple los horarios que le asignaron para integrarse a las trabajadoras del local. Hay doce personas listas de modo permanente para dar el servicio (el establecimiento cuenta con un máximo de doce puestos de trabajo), aunque en total son veinte trabajando. Se organizan en un sistema de turnos que incluye sábados y domingos, de diez de la mańana a nueve de la noche, respetando los horarios del centro comercial.

Las condiciones laborales de Vanesa son peores que las de otras trabajadoras de centros de estética que boletean. A ella le pagan el 35\% de lo que se cobra por su atención - menos que a otros de mis informantes- y sus horarios son más exigentes. Además, compite contra una sobreoferta de manicuristas; es raro que todos estén ocupados, por lo que cada día no alcanza a realizar muchas atenciones. A medida que llegan clientes se asignan a las empleadas siguiendo un orden, a menos que el cliente manifieste una preferencia. Para Vanesa un día bueno es cumplir con siete manos o pies, pero no ocurre a menudo. Lo usual es que sean tres y a veces ha regresado a casa sin atender una sola vez. Ella recibe en promedio alrededor de ciento cuarenta mil pesos, menos que el sueldo mínimo, pero prefiere este tipo de trabajo que ser parte de una empresa de aseo o empleada doméstica. Ser manicurista lo encuentra de señorita: le gusta que sea limpio, que huela bien, que las personas sean delicadas. De alguna manera ella es parte del mundo del negocio de los cosméticos y los tratamientos de belleza y eso le gusta, hasta que se enfrenta a las dificultades de un empleo sin regulaciones laborales.

Cuando fue despedida del anterior centro de estética fue sin ningún beneficio; en el actual ya ha tenido problemas porque son muy exigentes con la puntualidad y ella, viviendo lejos, se enfrenta a la ineficacia del transporte público. Además, las veces que ha estado enferma la han hecho llevar un certificado médico aunque no recibe pago por los días en que no trabaja; esto le 
significa ir al consultorio público a pedir el documento y esperar alrededor de tres horas para recibirlo.

Inge, depiladora de 48 años, confiesa reparos con su sistema de trabajo pero lo cuida, y pese a ser independiente paga todos los meses sus imposiciones en una Administradora de Fondos de Pensiones (Afr) y su cuota de Fonasa. ${ }^{5} \mathrm{Me}$ cuenta que casi nadie de sus compañeras lo hace: "solo las solas lo hacemos". Inge es madre soltera y labora en el mismo sitio de depilación desde hace más de diez años. Cuando empezó tenía contrato por el sueldo mínimo y el resto se lo pagaban como comisión (así, la empresa se ahorra un monto en impuestos y, si hay despido, se indemniza al empleado solo por el sueldo mínimo). Ahora cambió; ya no tiene contrato y ella entrega una boleta personal al cliente. Inge se queda con el $55 \%$ de lo que cuesta su atención, trabaja de lunes a sábado y tiene los martes libres. Ella, a diferencia de Vanesa, debe comprar todo lo que necesita para su trabajo: uniforme, ollas, cera y paletas, cremas, algodón y alcohol. Para Inge este acuerdo es lo mismo que el contrato por comisión porque sabe que no puede demorarse con un cliente para alcanzar el máximo de servicios al día, y tampoco puede faltar porque es día perdido.

Berta, en otro centro de depilación y estética, recibe el $60 \%$ de lo que se cobra por sus atenciones y le descuentan el costo de la cera depilatoria y las cremas que usa para sus masajes. Labora de lunes a sábado, de nueve de la mañana a ocho de la noche con una tarde libre. Su trabajo es más rentable que el de Inge y Vanesa tanto porque le pagan mayor porcentaje como porque el costo de los masajes es mucho mayor; entonces gana más. Aunque Berta estudió para peluquera al salir del colegio, realizó un curso de masajes después, cuando ya era depiladora en su actual centro de trabajo. Le dieron el tiempo para prepararse, pero el costo corrió por su cuenta, tanto en lo que se refiere a las atenciones que no hizo mientras se capacitaba como en cuanto al valor de la matrícula. Berta resultó ser muy buena masajista y tiene muchos clientes que piden atenderse con ella. Es una de las más exitosas del salón donde trabaja porque no le queda ni un espacio libre, lo que le significa una labor de once horas diarias, con un descanso para comer en el momento en que tenga la oportunidad:

Casi todos los días Berta tiene el horario completo. La llaman las clientas para pedir hora. Se llena con ellas y los espacios libres le toca atender a las personas que van sin anuncio, a depilarse o a un masaje. Sus clientas son muy fieles con

5 Las AFP son instituciones financieras privadas encargadas de administrar los fondos y ahorros de pensiones en Chile. Existen a partir de 1980, como fruto de la reforma previsional hecha por la dictadura de Pinochet. Fonasa (Fondo Nacional de Salud) fue creado en 1979 como continuador del sistema de recaudación y administración de los dineros estatales para las prestaciones de salud en Chile. 
ella, trabaja en Artemisa desde hace quince años. Cuando tiene el día muy copado se atrasa para almorzar y termina haciéndolo a las tres de la tarde, pero siempre se toma su descanso. Me dice que a su jefa no le gusta que no se tomen su hora de almuerzo. Tienen una cocina con hervidor, microondas, mesa y sillas para sentarse. Berta lleva su colación desde su casa. Sale como a las ocho de la tarde todos los días desde que empezó a trabajar más largo, cuando Felipe, su hijo menor, entró al colegio. (Notas de campo, 16 de noviembre, 2010).

Para Berta su trabajo es necesario por lo económico y porque le gusta. Aprecia la flexibilidad que le han dado, lo que le permitió trabajar menos horas, aunque con reducción de ingresos, cuando sus hijos eran pequeños. Pero en ciertos momentos no aprueba sus condiciones laborales. Cuando llega el tiempo de vacaciones se cuestiona. Es un periodo que no se lo pagan, sin embargo, no puede tomarse más de tres semanas debido a que en verano hay más demanda de masajes y depilación. También en las vacaciones de otras de sus compañeras su tarde libre desaparece porque debe sustituirlas y eso la deja agotada. La situación de sometimiento que experimenta Berta dista de ser poco reflexiva. Ella está al tanto de ventajas y desventajas de su forma de trabajo y racionalmente opta por él porque no encuentra alternativa mejor. Sin embargo, en todos los locales que formaron parte de la investigación, a pesar de que no haya una manifestación explícita de protesta frente a circunstancias laborales consideradas injustas, hay resistencia por parte de los trabajadores, la cual se manifiesta por medio de rumores y bromas sobre los supervisores, y de las muchas anécdotas y críticas que allí se cuentan.

Berta, como Inge y Vanesa, actúa como una empleada dependiente porque lo entiende como parte de su arreglo laboral. Además de usar uniforme y cumplir horario, está comprometida con la empresa: cada vez que atiende a una persona aprovecha para ofrecerle los demás servicios, informa a su jefa cómo le ha ido con las clientas, qué opina la gente de las nuevas máquinas de masajes y respeta los precios que impone la estética. Nunca se le ha ocurrido dar el servicio a sus clientes de manera independiente, cobrando más por ser a domicilio. En los quince años que ha laborado allí, solo ha parado durante las vacaciones de verano y por los nacimientos de sus hijos, eventos estos últimos en los que no solicitó el pago de su permiso pre y post natal porque no sabía que sí lo podía obtener como trabajadora independiente. Dice que su jefa es flexible y la deja ir al doctor o cumplir una diligencia si lo necesita, pero siempre a cambio de que ella reponga después el trabajo no hecho. Los horarios se arreglan entre las mismas empleadas y se cubren unas a otras. Cuando llega una máquina de masajes nueva les piden que vayan a las capacitaciones, pero no les pagan por esto, aunque sea un beneficio directo para la empresa, la cual es dueña de la 
máquina, y Berta y sus colegas pierden clientas mientras están aprendiendo a usar la nueva tecnología.

En el mismo centro, Rodrigo, podólogo de 53 años, recibe otro trato. No tiene que cumplir horarios, aunque él se asegura de estar todos los días, y cuando no acude deja dicho cuándo irá, para no perder a sus clientes. Hace seis años que llegó al centro de estética luego de trabajar como cobrador en fábricas de cecinas y ha aplicado su sistema de cálculo de ganancias, metas y proyecciones a su trabajo como podólogo. Él se ha propuesto crecer en ganancias un $10 \%$ cada año, y para eso combina su estancia en el centro con trabajo a domicilio, lo que es posible por su libertad de horarios. Si un día sabe que no hay muchos clientes y que solo hay dos horas reservadas, habla a sus clientes particulares para atenderlos. Berta no podría hacer eso porque, aunque tenga solo una reservación, debe permanecer en el centro por si aparecen clientas. En tiempos de invierno, cuando la demanda por depilación y masajes es menor, a Berta le aburre estar sentada sin hacer nada esperando la hora de cierre, pero no tiene opción; me dice que esas siempre han sido las condiciones y que ella sabe que la puerta es ancha.

Miguel, estilista en otro sitio también cumple horarios. Con 51 años, lleva siete trabajando allí. Su acuerdo consiste en que la peluquería se queda con $40 \%$ del cobro por la atención y él compra sus materiales, con excepción del champú y el bálsamo de la sección de los lavados. Su sueldo a fin de mes es bastante estable porque en donde trabaja hay un constante flujo de personas y no hay grandes cambios entre estaciones, como sucede con la depilación y los masajes. Él viste de negro a manera de uniforme, pero no está obligado a llevar el institucional. No tiene mayores problemas con la administración. Se ha ganado el respeto de los clientes, su experiencia es mucha y su agenda siempre está llena. Él es jefe de familia y aunque sus dos hijos ya son mayores de edad, todavía paga la universidad de uno de ellos. Además se hace cargo de cancelar el seguro de Isapre ${ }^{6}$ para él y su familia y la cuota para su previsión de jubilación.

\section{Materialidad y dominación}

En su análisis de la disciplina y la dominación, Foucault (1975) enfatiza especialmente en los dispositivos de control. Acerca de ello podemos señalar cómo las rutinas laborales en los salones de belleza están fuertemente reglamentadas y operan bajo un contrato de trabajo tácito que sustituye al escrito inexistente.

6 Las Isapre, o Instituciones de Salud Previsional, fueron creadas en 1981 a partir de la reforma que privatizó parte del sistema de salud durante la dictadura de Augusto Pinochet. 
El lugar de ese contrato es el cuerpo de las trabajadoras y es mediante su observación que se entienden los distintos niveles de intensidad con que suceden las relaciones de dominación y dependencia entre las trabajadoras y sus empresas. Es así que vemos cómo el nexo entre el trabajo y el cuerpo es crucial para la organización y la actualización de las relaciones laborales y, consecuentemente, la experiencia que las personas tienen de su cuerpo se encuentra muy ligada a su condición de empleados (Wolkowitz, 2006).

A Berta le duelen sus piernas. Su trabajo lo hace de pie. Además, camina todos los días seis cuadras desde la estación del metro al salón de belleza y otras tantas desde la estación del metro a su casa. Le gusta moverse, pero a fines de año se torció un tobillo y no ha podido recuperarse. No fue a consultar al doctor sino que se autorrecetó una venda elástica que la ayuda a no mover mucho el tobillo cuando camina. Después de varias veces que la vi cojeando le llevé una bota que había usado yo alguna vez cuando también me torcí un tobillo. Berta me la agradeció y me contó después que la usaba en su casa, pero no en el salón porque se veía desordenada. La bota kinesiológica era negra y nada estridente, pero para Berta parecer impecable y, sobre todo, apta para trabajar, era fundamental. Todas las trabajadoras de Artemisa deben comprar su uniforme: pantalones blancos y polera o casaca lila, según la estación. Vestir de uniforme es una corporeización de su sometimiento a las reglas del salón, junto con el cumplimiento de horarios y su uso del lugar. Solo pueden estar en sus cubículos, no les está permitido sentarse en la zona de espera aunque no hayan clientes, ni salir a la puerta del local a conversar y tomar aire fresco. Disponen de una sala para comer en la que, para cuando finalizaba mi trabajo de campo (fines de 2011), instalaron cámaras de video. Berta se molestó bastante con la medida y no entendía qué querían ver. Otra regla que genera resistencias es la obligatoriedad de asear el local. No hay personal contratado para ello por lo que las trabajadoras se turnan la limpieza de los cubículos y los espacios comunes. Rodrigo, el podólogo y único hombre trabajando en el salón, no participa del aseo.

Las condiciones disciplinarias que rigen la rutina de Berta son compartidas por las otras informantes. Uno de los principales problemas de Vanesa con su jefa es su impuntualidad, aunque llegue y no tenga a nadie a quien atender, y no se le pague por estar disponible. La presencia corporal de las trabajadoras en el salón, más allá de su quehacer, es parte del arreglo. Para los salones es importante mostrar disponibilidad de personal lo que se asocia a rapidez en la atención. Asimismo, los jefes de los salones cuidan que los materiales que utilizan sus empleados sean de buena calidad, aunque sean la mayoría de estos quienes los pagan. También hay acuerdos con los proveedores para que vendan sus productos en el salón: cremas para masajes, pinturas de uñas y productos capilares, principalmente. Miguel, por ejemplo, cuenta con un equipo de se- 
cadores y alisadores de pelo de alta calidad que le aseguran tanto un buen resultado con sus clientes, como el reconocimiento de sus jefes.

\section{Dominación y competencias críticas}

Los estados de vida de las informantes ayudan en gran medida a entender de qué modo las trabajadoras pueden vivir sin seguro social. Las mujeres que aprovechan la inscripción de sus maridos en el sistema de salud para atenderse y que, por otra parte, no ven como necesario contar con una jubilación en el futuro, parece estar extendido en los centros de belleza, ya que las entrevistadas refirieron a varias de sus colegas en esa situación. Por su parte, las más jóvenes sin hijos ni responsabilidades económicas con sus familias de origen conciben el trabajo como una oportunidad para aprender más que como una fuente de ingresos. Llama la atención el desparpajo con que Vanesa da cuenta de su situación en una conversación registrada en mis notas de campo:

Vanesa este mes casi no recibirá sueldo porque se juntaron los días de fiestas no trabajados, un adelanto que ella pidió para tener para el dieciocho de septiembre, ${ }^{7}$ y los días que ella estuvo enferma y no trabajó. "Si me salen diez mil pesos, prefiero que no me paguen y acumularlos", dice, porque cree que eso es lo máximo que va a sacar. Yo le pregunto si es que acaso ella no tiene compromisos, cosas que pagar, y me dice que le debe plata a su madrina, a la que le pidió para comprarse unas zapatillas, y que lo demás ya lo pagó (la cuenta de su celular). A su mamá le dio cincuenta mil pesos y dice que se los podría pedir de vuelta y volver a dárselos después. Ella los tiene guardados para el cumpleaños de su hermana pequeña, que quiere ir a Fantasilandia, un parque de diversiones. Vanesa dice que el 15, cuando le toque paga de nuevo, se los puede volver a pasar. (Notas de campo, 1 de octubre 2010).

Desde otro punto de vista, el que muchas de las mujeres casadas o jóvenes sin familia perciben su trabajo como una actividad con ingresos que complementan los de sus padres o maridos, facilita que se impongan ciertas formas de empleo. Los salones de belleza en Chile son mayormente atendidos por mujeres $y$, en ese contexto, la masificación de la informalidad dependiente, disfrazada de formalidad al exigir que las empleadas entreguen una boleta de servicios, se ha vuelto en la manera de operar del rubro. Las entrevistadas dieron cuenta de que son escasas las ofertas de puestos laborales con contrato en las peluquerías y

7 Fiesta de la independencia nacional, entonces los trabajadores formales reciben habitualmente un aguinaldo como parte de sus beneficios laborales. 
que la única alternativa es aceptar las condiciones que hay. Es significativo que sean los hombres los que obtienen mejores arreglos laborales ya que supone la creencia de que probablemente no podrían aceptar peores condiciones debido a sus responsabilidades familiares.

La combinación de estados de vida con una cultura machista en la que se percibe el ingreso de la mujer — cuando no se trata de jefas de hogar- como un aporte al ingreso principal de la familia, lo que Zelizer (2011) denominó "plata marcada", entrega el contexto ideal para que se funden y reproduzcan estructuras de dominación laboral particulares asociadas a grupos específicos de trabajadoras y rubros de servicios. La inexistencia de alternativas facilita la imposición de condiciones fuera de todo derecho laboral, sin que exista fiscalización de parte del Estado ni resistencia por parte de los clientes a contratar este tipo de prestaciones.

A pesar de todo, las trabajadoras establecen equivalencias entre distintas situaciones e identifican las que les parecen injustas (Boltanski \& Thévenot, 1991). Aquí la pregunta es cómo se perpetúa la dominación a pesar de las críticas de las trabajadoras. Una primera respuesta sería que las críticas proceden de las trabajadoras que están al tanto de sus desventajas, pero que se mantienen en sus empleos porque carecen de otras alternativas. Sus posibilidades de expandir sus competencias críticas, tematizarlas y hacerlas existir frente a sus empleadores y empleadoras, son escasas; las trabajadoras de los salones de belleza no están asociadas y existe en ese ámbito laboral una alta rotación de empleadas.

Una segunda respuesta, más importante aún, es que las diferencias en las ganancias de las diferentes trabajadoras, según su especialidad y habilidad para atraer clientes, inciden en que las experiencias de dominación no sean percibidas con la misma fuerza y que muchos de los reparos que expresan en algún momento sean minimizados en otro: "Ninguna dominación se acepta por sí misma si no se 'justifica' por estrictas consideraciones funcionales" (Martuccelli, 2007: p. 139). Y para las trabajadoras con un ingreso razonable, las condiciones, por injustas que parezcan, valen la pena. Las críticas no alcanzan la fuerza necesaria para demandar cambios o fiscalizaciones y así la heterogeneidad de este grupo de trabajadoras, no susceptible de encasillar en una categoría, contribuye a conservar esa forma de dependencia.

\section{El rebalse de las categorías}

Dentro de un análisis del uso del término trabajador informal, la figura de los trabajadores independientes/dependientes ilumina varios aspectos relacionados con las regulaciones obligadas para el trabajo formal, y que desbordan los 
temas de la previsión social y el seguro de salud. El trabajo de Miguel, Inge y Rodrigo, como el de Vanesa y Berta, no está regulado por el código del trabajo. Ellos no están protegidos contra abusos de sus empleadores, ni contra accidentes, no tienen derecho a vacaciones ni a indemnización, sus opciones para obtener un seguro de cesantía son más engorrosas que si tuviesen un contrato y no hay espacios para la capacitación a cargo del empleador.

Sin embargo, a pesar de ello, el trabajo independiente/dependiente es atractivo para aquellos que prestan servicios caros y que lo que más les cuesta es conseguir clientes, como para el podólogo y la masajista. Es atractivo para Miguel, que tiene una clientela que lo sigue, pero que precisa de un lugar para prestar sus servicios. Su alternativa sería instalar su propia peluquería, pero ello requiere de un capital. El trabajo independiente/dependiente dista de ser un trabajo de bajos ingresos para las personas más especializadas, e incluso, según los términos con los que se construya la relación de dominación, puede ser un empleo flexible, como lo es para Rodrigo. Los grandes perdedores son los trabajadores fácilmente permutables, con oficios que requieren poca capacitación, como lo son la manicurista y la depiladora. Ellas están expuestas a la mayor cantidad de abusos y si no aceptan esas condiciones, el costo de su reemplazo para el empleador es casi nulo.

En esta línea, la ciudad por proyectos (Boltanski \& Chiapello, 2002), aquel marco de entendimiento en el que los individuos buscan formar relaciones de confianza, cara a cara, colaboraciones y alianzas para lograr sus objetivos en un encuadre de flexibilidad, ayuda a distinguir la multiplicidad de casos que se dan bajo la etiqueta de trabajador independiente/dependiente y sus consecuentes realidades. Mientras algunos enfrentan su situación laboral como un proyecto del cual la empresa para la que trabajan no es más que un punto para establecer conexiones, otros se ven inmovilizados por ella. El espacio laboral aparece como oportunidad o control para el despliegue de la creatividad y la autodeterminación, a cambio del flujo de clientes que ofrece la empresa a sus trabajadores.

En tanto que los individuos que se inscriben con éxito en la gramática de la ciudad por proyectos son los que logran los ingresos que se proponen a fuerza de autoimponerse largas jornadas de trabajo, prescindiendo de las vacaciones y los días libres. Desplegando disciplina, ambición y flexibilidad, maximizan sus ganancias. Se trata de una modalidad laboral que ellos controlan siempre y cuando exista demanda, y para que así ocurra, los trabajadores despliegan creatividad y aprovechan las condiciones de su empresa para crear conexiones y especializar sus servicios. Las nuevas estrategias laborales desplegadas en el sector formal de la economía descritas por Sennett (2006) son similares a las de las trabajadoras independientes/dependientes: se adaptan constantemente al cambio, manejan múltiples metas de manera paralela y se autogobiernan. 
Es notable cómo la autogobernanza de la que habla Sennett en el contexto formal de la economía, en el que según el análisis del autor se debilitan los lazos sociales al interior de la empresa y el autogobierno opera como ordenador en su reemplazo, es clave para las independientes/dependientes puesto que de ella depende cuánto produzcan y cuánto ganen.

Para Rodrigo las vacaciones no existen. No se toma un día libre desde hace seis años. La disciplina, en sus palabras, es la clave para su trabajo. Él es constante y acude todos los días a trabajar, tenga o no clientes agendados, porque cree que si sus clientes no lo encuentran, los pierde. Cuando pasa mucho tiempo sin ver a alguno lo llama por teléfono y le ofrece sus servicios a domicilio y de esa forma intenta siempre estar ocupado. Dice: "cuando jubile, si alguna vez jubilo", porque él se visualiza trabajando siempre, hasta que pueda. Su receta, como dice él, no se la aconseja a nadie, porque implica sacrificar mucho: "vida familiar, principalmente”. Él está siempre listo para atender al cliente que lo llame, aunque sea el domingo a las siete de la tarde. Él cree que mucha gente no está dispuesta a sacrificarse por el trabajo y que por eso les es difícil. En cambio él, cuando decidió dedicarse de tiempo completo a la podología de manera independiente, se planteó trabajar de modo sistemático e intenso para probar si el negocio era bueno, y así ha sido.

Rodrigo, a pesar de no tener un contrato, comparte con otros empleados chilenos lo que Araujo \& Martuccelli (2012) han llamado la desmesura laboral. Esta se refiere al carácter de las demandas laborales contemporáneas que provocan en los individuos una percepción de sobreexigencia y de presión, empujando constantemente a la acción y generando una experiencia de transgresión de los límites propios: "Las desmesuras de lo laboral aparecen, principalmente, en forma de sobrerrequerimientos temporales, relacionales, de toma de riesgos, de aguante a la inestabilidad y el cambio, y de producción de sentido" (Araujo \& Martuccelli, 2012: p. 17). No deja de ser interesante que esta desmesura laboral, vinculada en un principio a los nuevos órdenes de la empresa capitalista actual, sea vivida por quien se autodefine como un emprendedor.

\section{Emprendimiento y trabajo informal}

Los valores tradicionalmente adscritos al empresariado tales como creatividad, empuje, disciplina laboral y autocontrol, se comparten cada vez más con los que esgrimen las trabajadoras informales que no se perciben como tales sino como independientes, por ejemplo, Rodrigo o Miguel. Se sienten responsables de su suerte y dueñas de su destino. En cambio, las menos exitosas no ven real diferencia entre su forma de trabajo y uno regulado por contrato porque 
sus beneficios económicos son igual de precarios. No visualizan los derechos vinculados al contrato de trabajo por desinformación o porque cuando lo han tenido ha sido por el ingreso mínimo, y muchas veces no han defendido que se les respeten el pago de horas extra y vacaciones.

Es significativo cómo elementos claves para asegurar condiciones de trabajo dignas como el sindicalizarse u otras posibilidades de agrupación y capacitación están ausentes en la experiencia y las narrativas de estas trabajadoras. Frente al valor del emprendimiento y el esfuerzo personal no se levantan valores relevantes que ofrezcan alternativas como el bien común o la creación colectiva. Se trata de una cultura altamente individualizada, incluso entre las trabajadoras que son críticas de su arreglo laboral. Lo que se busca es el bienestar individual.

La fuerza con que la cultura neoliberal ha permeado la esfera laboral en Chile se ha documentado reiteradamente (Araujo \& Martuccelli, 2012; Cárdenas, Link \& Stillerman, 2012; PNUD, 2009), y aunque algunos apuntan a la legislación como la causa de que se permitan prácticas indebidas, muchas veces son las mismas trabajadoras las que promueven un sistema en el que se privilegia el beneficio económico por sobre las condiciones de trabajo.

En este contexto, las trabajadoras independientes/dependientes son vistas como una oportunidad para maximizar ganancias. Es una modalidad laboral que opera como una suerte de subcontratación pero sin contratista de por medio. La empresa se libera de responsabilidades ligadas a un contrato y el empleado pasa a ser parte de un conjunto disponible de prestadores de servicios. La trabajadora independiente/dependiente está reemplazando a la empleada necesitada por la empresa, por lo que es una estrategia ideada para ahorrar en costos de contratación, despido y otros, de una manera más eficiente que la subcontratación, la cual se llevaría alguna ganancia por establecer el vínculo con los trabajadores.

Esta nueva estrategia de complementariedad del sector informal con el formal, en el marco de un sistema económico que siempre busca maximizar ganancias, permite que hayan trabajadoras que optarán por la informalidad para obtener un ingreso inmediato mayor, el que proviene, en primer lugar, de no tener descuentos para fondos de previsión y salud (en los que no siempre confían, perciben como innecesarios o, en su opinión, no necesitan ya que son carga de sus cónyuges), y, en segundo lugar, de la posibilidad de tener un ingreso flexible que crece gracias a la captación de una mayor cantidad de clientes.

La investigación detallada de las prácticas de trabajo informal dialoga de manera fructífera con la perspectiva de Alejandro Portes y empuja a examinar la informalidad como un sector de la economía con dinámicas propias y funcionales al modelo capitalista imperante y que no se supera con la modernización de la economía. Asumir que el sector informal es un fenómeno persistente y, algunas veces, creciente, que no cambia sustancialmente junto a los ciclos de la 
economía global y que no depende de la modernización ni del desarrollo de las economías, implica mover la discusión hacia los modos en que los trabajos informales pueden constituir formas de trabajo decente. El camino a la formalización debe adoptar mecanismos que no hagan desaparecer estos puestos laborales que no solo constituyen el ingreso de muchas personas, sino que también son claves para el funcionamiento de sectores formales de la economía.

\section{Referencias}

Abramo, L. (1998). The sociology of work in Latin America. A complex development and current challenges. Work and Occupations, 25(3), 305-332.

Araujo, K.\& Martuccelli, D. (2012). Desafíos comunes. Retrato de la sociedad chilena y sus individuos. Santiago: LOM Ediciones.

Beck, U. (2003). La individualización. Barcelona: Paidós.

Boltanski, L. \& Chiapello, É. (2002). El nuevo espiritu del capitalismo. Madrid: Akal.

Boltanski, L. \& Thévenot, L. (1991). De la justification. Les économies de la grandeur. París: Gallimard.

Cárdenas, A., Link, F. \& Stillerman, J. (2012). ¿Qué significa el trabajo hoy? Cambios en una sociedad global. Santiago: Catalonia.

Foucault, M. (1988). Technologies of the self en technologies of the self: A seminar with Michel Foucault. Amherst, MA: University of Massachusetts Press.

Foucault, M. (1975). Discipline and punish. The birth of the prison. Nueva York: Penguin.

Geertz, C. (1973). La interpretación de las culturas. Barcelona: Gedisa.

Hart, K. (1970). Small Scale Entrepreneurs in Ghana and Development Planning. The Journal of Development Studies, 6(4), 104-120.

Henríquez, H., Cárdenas, A. \& Selamé, T. (2005). Trabajo a domicilio en el siglo XXI: Tres miradas sobre el teletrabajo. Cuaderno de Investigación, 26. Santiago de Chile: Dirección del TrabajoDepartamento de Estudios-Gobierno de Chile.

Martuccelli, D. (2007). Cambio de rumbo. La sociedad a escala del individuo. Santiago: LoM Ediciones. 
Organización Internacional del Trabajo (ОIт) (1972). Employment, Incomes and Equality: a Strategy for Increasing Productive Employment in Kenya. Ginebra: OIT.

Palacios, R. (2011). ¿Qué significa ser trabajador informal? Revisiones desde una investigación etnográfica. Revista Mexicana de Sociología, 73(4), 591-616.

Portes, A. (2010). Economic sociology. A systematic inquiry. Princeton y Oxford: Princeton University Press.

Portes, A. \& Haller, W. (2004). La economía informal (pp. 1-55). Santiago: cepal (Políticas Sociales, 100).

Programa de las Naciones Unidas para el Desarrollo (PNUD) (2009). Desarrollo humano en Chile. La manera de hacer las cosas. Santiago: PNUD.

Rose, N. (1998). Inventing our selves. Psychology, power and personhood. Cambridge: Cambridge University Press.

Savage, M. (2009). Contemporary sociology and the challenge of descriptive assemblage. European Journal of Social Theory, (12), 155-174.

Sennett, R. (2006). La cultura del nuevo capitalismo. Barcelona: Anagrama.

Tokman, V. (2007). Informality: Exclusion and precariousnes. Enabling Transition to Formalization. Background document. Tripartite International Symposium on the Informal Economy. Ginebra. International Labour Organization.

Wolkowitz, C. (2006). Bodies at work. Londres: Sage.

Zelizer, V. (2011). The social meaning of money: Special monies. En Zelizer, V. Economic Lives. How Culture Shapes the Economy (pp. 93-127). Princeton y Oxford: Princeton University Press.

Recibido el 20 de julio de 2015. Aceptado el 20 de enero de 2017. 